\title{
Erratum to: Modeling key pathological features of frontotemporal dementia with $C 9 O R F 72$ repeat expansion in iPSC-derived human neurons
}

\author{
Sandra Almeida $\cdot$ Eduardo Gascon · Hélène Tran $\cdot$ Hsin Jung Chou $\cdot$ Tania F. Gendron $\cdot$ Steven DeGroot $\cdot$ \\ Andrew R. Tapper · Chantal Sellier · Nicolas Charlet-Berguerand • Anna Karydas · William W. Seeley • \\ Adam L. Boxer · Leonard Petrucelli · Bruce L. Miller · Fen-Biao Gao
}

Published online: 9 April 2014

C) Springer-Verlag Berlin Heidelberg 2014

Erratum to: Acta Neuropathol (2013) 126:385-399

DOI 10.1007/s00401-013-1149-y

We regret that the $p$ value was not indicated for Fig. 6c. Below is the revised Fig. 6.

Fig. 6 C9ORF72 repeat expansions form RNA foci in patient iPSCs-derived neurons. Expression levels of C9ORF72 variant 1 (NM_145005.5, isoform b) (a), variant 2 (NM_018325.3, isoform a) (b) and variant 3 (NM_001256054.1, isoform a) (c) in iPSC-derived neurons from two non-carriers and two expanded repeat carriers were assessed by qRT-PCR. Values are mean \pm SEM, $* * * p<0.001$, ${ }^{*} p<0.05$ (Student's $t$ test). FISH analysis was done on control iPSCderived neurons (d), carrier 1 line 6 iPSC-derived neurons (e), carrier 2 line 11 iPSC-derived neurons (f) using a cy3-conjugated (GGC$\mathrm{CCC})_{4}$ probe. Green MAP2. Blue DAPI. Scale bar $10 \mu \mathrm{m}$. Quantifications of the percentage of neurons displaying foci (g) and the average number of foci per cell (h) are presented as mean \pm SEM, based on analysis of neurons derived from three independent differentiation experiments. Gly-Pro dipeptide repeats are detected by dot blot analysis in neurons of carrier 1 (iPSC lines 5 and 6) and carrier 2 (iPSC lines 1 and 11) (i)

The online version of the original article can be found under doi:10.1007/s00401-013-1149-y.

S. Almeida · E. Gascon · H. Tran · H. J. Chou · F.-B. Gao $(\bowtie)$ Department of Neurology, University of Massachusetts Medical School, Worcester, MA 01605, USA

e-mail: fen-biao.gao@umassmed.edu

T. F. Gendron · L. Petrucelli

Department of Neuroscience, Mayo Clinic Florida, Jacksonville, FL 32224, USA

\section{S. DeGroot · A. R. Tapper}

Department of Psychiatry, Brudnick Neuropsychiatric Research Institute, University of Massachusetts Medical School, Worcester, MA 01604, USA
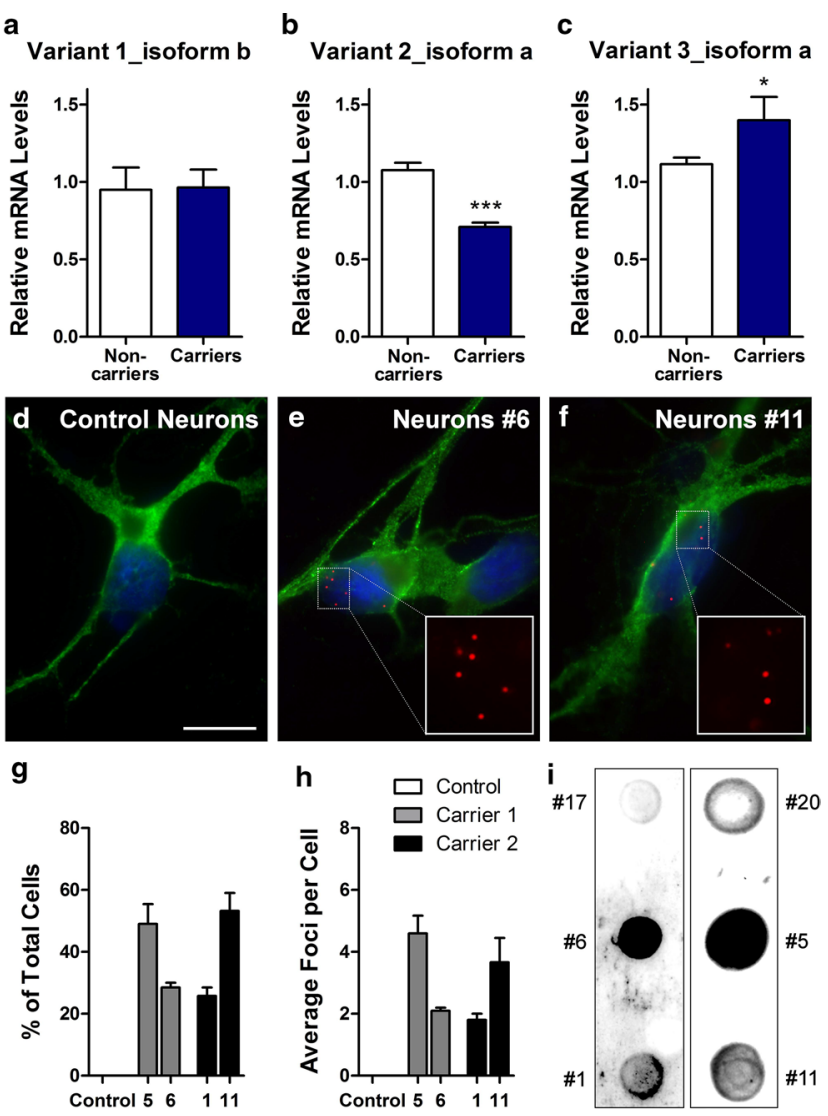

C. Sellier $\cdot$ N. Charlet-Berguerand

Department of Neurobiology and Genetics, IGBMC, INSERM, U964, CNRS UMR7104, University of Strasbourg, Illkirch, France

A. Karydas · W. W. Seeley · A. L. Boxer · B. L. Miller Department of Neurology, Memory and Aging Center, University of California, San Francisco, CA 94143, USA 